\title{
MiR-141 Activates Nrf2-Dependent Antioxidant Pathway via Down-Regulating the Expression of Keap1 Conferring the Resistance of Hepatocellular Carcinoma Cells to 5-Fluorouracil
}

\author{
Liang Shi ${ }^{\mathrm{a}}$ Lili Wu ${ }^{\mathrm{b}}$ Zhanguo Chen ${ }^{\mathrm{a}}$ Jianrong Yang ${ }^{\mathrm{a}}$ Xiaofei Chen ${ }^{\mathrm{a}}$ \\ Fangyou Yu ${ }^{a}$ Fang Zheng ${ }^{c}$ Xiangyang Lin ${ }^{a}$
}

aDepartment of Laboratory Medicine, The First Affiliated Hospital of Wenzhou Medical Uinversity, Wenzhou, China, bDepartment of Clinical Laboratory, The Dingli Clinical College of Wenzhou Medical University, Wenzhou, 'Center for Gene Diagnose, Zhongnan Hospital of Wuhan University, Wuhan, China

\section{Key Words}

MiR-141 • Keap1 • 5-fluorouracil • Chemoresistance • Hepatocellular Carcinoma

\begin{abstract}
Background: Hepatocellular carcinoma (HCC) is one of the most lethal malignancies worldwide. A major cause for the failure of cancer therapy is the development of chemoresistance. Although progress has been made in the study of the mechanisms underlying cancer cells resistance, little is known about the role of microRNAs (miRNAs) in cancer therapy resistance. Methods and Results: Fifteen miRNAs, including 6 up-regulated miRNAs (> 2.0-fold) and 9 down-regulated miRNAs $(<0.5$-fold) were differentially expressed in 5-fluorouracil-resistant and their parental cell-lines (HepG2, HepG2/5-FU) by miRNA microarrays. Microarray results were confirmed by validating quantitative real-time polymerase chain reaction (qRT-PCR) analysis. Up-regulation of miR-141 expression resulted in a significant inhibition of 5-FU-mediated cytotoxicity and apoptosis in various hepatocellular carcinoma cells-lines. Mechanically, miR-141 promoted Kelch-like ECH-associated protein 1 (Keap1) mRNA degradation by directly targeting the Keap1 3'untranslated region (3'UTR). Treatment with miR-141 mimics in parental HepG2 cells, restored miR-141 expression and reduced Keap1 levels, thereby resulting in erythroid transcription factor NFE2-L2 (Nrf2) nuclear translocation, activation of Nrf2-dependent HO-1 gene transcription, and subsequent enhancement in 5-FU resistance. Conversely, restoring the expression of Keap1 partly recovered 5-FU sensitivity by counteracting miR-141-mediated 5-FU resistance. Conclusion: Our study showed that miR-141 plays a key role in 5-FU resistance by down-regulating Keap1 expression, thereby reactivating the Nrf2-dependent
\end{abstract}

L. Shi, L. Wu and Z. Chen contributed equally to this work.

Xiangyang Lin, Fang Zheng

and Fangyou Yu

KARGER 125
Department of Laboratory Medicine, The First Affiliated Hospital of Wenzhou Medical

Uinversity, 3\# Fuxue lane, Wenzhou325000 (China)

E-Mail shiliang6666@126.com, linxy1968@126.com and zhengfang@whu.edu.cn 
antioxidant pathway, which may serve as a potential target for overcoming 5-FU resistance in hepatocellular carcinoma cells.

Copyright $\odot 2015$ S. Karger AG, Basel

\section{Introduction}

Hepatocellular carcinoma is one of the most common cancers regarding to both incidence and mortality. Although a small subset of HCC patients are qualified for conventional therapies, such as surgical intervention, radiotherapy, chemotherapy, and targeting therapy, many patients particularly with tumor thrombi in the major trunk of the portal vein are associated with little chance of survival [1]. The extremely poor prognosis of HCC is mainly attributed to high rate of the occurrence of acquired drug resistance. Extensive research findings have suggested that causes of cancer-specific drug resistance are associated with the increased detoxification of anticancer drug, inactivated apoptosis pathway, alterations of deoxyribonucleic acid (DNA) repair or DNA tolerance, decreased uptake of water-soluble drugs, and increased drug efflux from cancer cells mediated by adenosine triphosphate (ATP) binding cassette (ABC) transporters [2]. In addition, recent studies have shown that epigenetic alterations, including DNA methylation and histone modifications are also linked with acquired clinical resistance following anticancer therapy [3].

MicroRNA is a small noncoding, single-stranded ribonucleic acid (RNA) gene product, which post-transcriptionally modulates the gene expression by down-regulating the stability or inducing the degradation of mRNAs by exhibiting fully complementary target sites. MicroRNA plays a critical role in various biological processes, such as cell differentiation, proliferation, and apoptosis [4]. Aberrant levels of miRNAs have been widely reported in various kinds of human cancers with up- and down-regulation detection in neoplastic cells as compared to their normal counterparts. The ectopic expression has been reported to have both diagnostic and prognostic significance and acts as a novel target for cancer therapy [5]. Currently, accumulating studies indicated that chemoresistance in several types of cancers may also be regulated by the changes in miRNAs levels, which constitute potential oncogenes or tumor suppressors [6]. It has been reported that cisplatin resistance was enhanced due to ectopic expression of miR-214,miR-376c, and miR-125b by inhibiting PTEN, ALK7 and BAK1, respectively, in ovarian cancer cell-lines [7-9]. Fujita et al. [10] reported that chemoresistance in prostate cancer cells was attenuated by overexpression of miR-34a. Furthermore, miR-122 was also found to be significantly related with the sensitivity to sorafenib and doxorubicin [11]. To date, the involvement of miRNAs in 5-FU resistance, however, is not confirmed in HCC cells.

The hypothesis of this study is that up-regulation of miRNA expression might contribute to the acquisition of resistance to 5-FU in HCC cells. The 5-fluorouracil resistant HepG2 cell-line (HepG2/5-FU) was established in our lab. Based on the miRNA microarray data, a pronounced deregulation of miRNA expression was exhibited in HepG2/5-FU cells as compared to their parental counterparts. Moreover, miR-141 was up-regulated in HepG2/5FU cells and conferred 5-FU resistance when overexpressed in various HCC cells-lines. It has been demonstrated that Keap1 is a direct target of miR-141 in HepG2 cells, and miR141 mediates 5-FU resistance through the suppression of Keap1 expression. Furthermore, Transfected with miR-141 mimics in HepG2 cell line, led to miR-141 restoration and Keap1 inhibition, which ultimately resulted in re-activation of the Nrf2-dependent antioxidant pathways and subsequent enhancement of 5-FU resistance. Interestingly, co-transfection with anti-miR-141 partly restored the expression of Keap1 and recovered 5-FU-induced cytotoxicity and apoptosis. Taken together, our findings suggested that regulation of Keap1 by miR-141 plays an essential role in the cellular resistance to 5-FU. 


\section{Cellular Physiology Cell Physiol Biochem 2015;35:2333-2348 \begin{tabular}{ll|l} 
and Biochemistry 10.1159/000374036 & $\begin{array}{l}\text { Published online: April 15, } 2015 \text { S. Karger AG, Basel } \\
\text { www.karger.com/cpb }\end{array}$ \\
\hline
\end{tabular} \\ Shi et al.: MiR-141 and 5-Fluorouracil-Resistance}

\section{Materials and Methods}

\section{HCC cell line and cell culture}

The human HCC cell lines, including HepG2, SMMC-7721, and HuH7 were purchased from the China Military Medical Science Academy of the PLA (Beijing, China), 5-FU was purchased from Zhejiang Haizheng Pharmaceutical Co., Ltd. (China), and resistant cells were developed from their parental cells by exposure to gradually increasing doses of 5-FU in cell culture medium. All the cells were cultured in Dulbecco's modified Eagle's medium (DMEM) (HyClone) supplemented with 10\% fetal bovine serum (FBS) (Gibco BRL, Grand Island, NY) and $100 \mathrm{U} / \mathrm{mL}$ penicillin and $100 \mathrm{mg} / \mathrm{mL}$ streptomycin at $37^{\circ} \mathrm{C}$ in a humidified incubator with $5 \%$ carbon dioxide $\left(\mathrm{CO}_{2}\right)$ at room temperature. The 5 -fluorouracil resistant cells were cultured for one week in a medium without 5-FU prior to experiments. Exponentially growing cells were used for all the experiments.

\section{MiRNA microarrays and data analysis}

Total RNA was isolated from HepG2 and HepG2/5-FU cells using TRIzol Reagent (Invitrogen) according to the manufacturer's instructions. Small RNA was prepared by using a mirVana kit (Ambion, Austin, USA) and labeled with Cy3 and Cy5 fluorescent dyes, which were applied for hybridization to dualchannel microarrays on each chip containing 1344 probes capable of detecting 725 human miRNAs as well as rodent miRNAs in triplicates. Raw data was normalized and adjusted using the GenePix Pro 4.0 software. The student's $t$-test analyses were carried out between HepG2 and HepG2/5-FU samples, and miRNA with $p$ values of $<0.05$ were chosen for cluster analysis using a hierarchical method and average linkage and Euclidean distance metric.

\section{Real-time quantitative PCR}

Total cellular RNA was extracted using TRIzol reagent according to the manufacturer's instructions. Reverse transcription and PCR were performed using SYBR RT-PCR kits detection system (Toyobo, Japan) with the following cycles: $95^{\circ} \mathrm{C}$ for $1 \mathrm{~min} ; 9^{\circ} \mathrm{C}$ for $15 \mathrm{~s} ; 58^{\circ} \mathrm{C}$ for $20 \mathrm{~s}$, and $72^{\circ} \mathrm{C}$ for $20 \mathrm{~s}\left(40\right.$ cycles); and $72^{\circ} \mathrm{C}$ for 5 min. Primer sequences are as follows:

Keap1: 5'-TAC GAT GTG GAA ACA GAG ACG TGG A-3'(forward), 5'-TCA ACA GGT ACA GTT CTG GTC AAT CT-3'(reverse); Nrf2: 5'-TGA GGT TTC TTC GGC TAC GTT-3'(forward), 5'-CTT CTG TCA GTT TGG CTT CTG G-3' (reverse); HO-1: 5'-CTG GAG GAG GAG ATT GAG CG-3'(forward), 5'-ATG GCT GGT GTG TAG GGG AT-3'(reverse); $\beta$-actin: 5-'CCA CAC CTT CTA CAA TGA GC-3'(forward), 5'-GGT CTC AAA CAT GAT CTG GG3 '(reverse).

The data was collected and calculated using the comparative Ct method and normalized to $\beta$-actin.

One step qRT-PCR analysis for miRNA expression

Total RNA was extracted from the cell lines using Trizol reagent, and miRNA fraction was further purified by mirVana miRNA isolation kit. Ribonucleic acid samples were detected spectroscopically for their concentration and purity. Expression of mature miRNA was assayed using EzOmicsTM One-Step qPCR Kit (Biomics Biotechnologies Co., Ltd, Nantong, China). U6 small nuclear RNA (snRNA) was used for normalizing the relative amount of each miRNA. The primers specific for human miR-141, miR-21, miR-27a, miR-155, miR-210, miR-134, miR-340, miR-145, miR-451, miR-19a, miR-148a, miR-565, miR-501, miR-29a, miR-30a, and U6 were obtained from EzOmicsTM miRNA qPCR Detection Primer Set. Quantitative real-time polymerase chain reaction was performed on a SmartCycler (Cepheid) at $42^{\circ} \mathrm{C}$ for $30 \mathrm{~min}$; $95^{\circ} \mathrm{C}$ for $10 \mathrm{~min}$, followed by 40 cycles of amplification at $95^{\circ} \mathrm{C}$ for $20 \mathrm{~s}, 62^{\circ} \mathrm{C}$ for $30 \mathrm{~s}$, and $72^{\circ} \mathrm{C}$ for $30 \mathrm{~s}$. The melt curve stage was performed at $95^{\circ} \mathrm{C}$ for $30 \mathrm{~s}, 60^{\circ} \mathrm{C}$ for $30 \mathrm{~min}$, and $95^{\circ} \mathrm{C}$ for $30 \mathrm{~s}$. The fold change for miRNA from HepG2/5FU cells relative to control HepG2 cells was calculated using the ${ }^{2 \triangle C T}$ formula. Polymerase chain reaction was performed in triplicates.

Transfection of miR-141 mimics or anti-miR-141

MiR-141 mimics and inhibitors were obtained from Genepharma (Shanghai, China). The sequences were as follows: miR-141 mimic: sense: 5'-UAA CAC UGU CUG GUA ACG AUG U-3', antisense: 5'-ACA UCG UUA CCA GAC AGU GUU A-3'; miR-141 inhibitor: 5'-ACA UCG UUA CCA GAC AGU GUU A-3'.

MiR-141 mimics and its negative control were used in HepG2, SMMC-7721, and HuH7 cells with low miR-141 expression, and miR-141 inhibitors and its negative control were used in HepG2/5-FU and SMMC- 
7721/5-FU cells with high miR-141 expression. Oligofectamine transfection reagent or lipofectamine 2000 (Invitrogen) was used for transfection. Cells were seeded in a 6-well plate at a density of $2 \times 10^{5}$ per well in DMEM with $10 \%$ FBS, without antibiotics. After $24 \mathrm{~h}$, the cells were transfected with miR-141 mimics or miR-141 inhibitors or their negative control using lipofectamine 2000 according to the manufacturer's protocol. The cells were collected for further analysis after $48 \mathrm{~h}$.

Vector construction and dual-luciferase reporter assay

To construct a luciferase reporter with the wild-type Keap1 3'UTR, the 3'UTR of Keap1 downstream of the luciferase gene was placed in the pGL3-control vector (Promega, Madison, WI) and was digested with NheI and XhoI (Biomics Biotechnologies Co. Ltd., Nantong, China). The Keap1 3'UTR sequences were amplified by PCR from genomic DNA using the following primers: 5'-ACG TAC GCT AGC GAA GCA GAT TGA CCA GCA GA-3'(forward), 5'-ACG TAC CTC GAG ATG CGA TGG GCA AAG ATT AC-3' (reverse).

The mutated pGL3-Keap1 3'UTR was constructed with point mutations within the potential miR-141 binding site using two sets of primers: 5'-GAA GGG AGG CCA GGA TGC CTG ACT CTT AAA ATG ACA TCT CAA AAGA-3' (forward), 5'-TCT TTT GAG ATG TCA TTT TAA GAG TCA GGC ATC CTG GCC TCC CTT C-3' (reverse).

These two fragments were annealed and used as templates to amplify a mutated Keap1 3'UTR. The resulting mutant exhibited 3 point mutations ( $C$ ( $C$ to $A$ ), AGU ( $U$ to $C$ ), and $G$ ( $G$ to $U$ ) $U U A$ ) as confirmed by sequencing. HO-1-ARE luciferase plasmid contained HO-1 promoter, including the ARE region as described previously [12].

For the luciferase assay, cells, seeded at $1.5 \times 10^{5}$ per well in 24 -well plates, and were co-transfected with $50 \mathrm{ng}$ of luciferase reporter plasmids containing wild-type or mutated 3'UTR of Keap1 and miR-141 mimics or anti-miR-141 or negative control $(100 \mathrm{nM})$ using lipofectamine 2000 (Invitrogen) according to the manufacturer's protocol. The pRL-TK vector (Promega) was used as an internal control. The luciferase activity was measured after $48 \mathrm{~h}$ of transfection using the dual-luciferase reporter assay system (Promega). Firefly luciferase activity was normalized to renilla luciferase activity for each transfected well. Independent experiments were performed in triplicates.

\section{Western blot analysis}

Whole-cell extracts and nuclear extracts were prepared as described previously [12]. The proteins were separated using $10-15 \% \mathrm{w} / \mathrm{v}$ sodium dodecyl sulphate polyacrylamide gel electrophoresis (SDSPAGE) and were transferred onto a nitrocellulose membrane (Bio-Rad). After blocking with $5 \%$ nonfat dry milk in phosphate-buffered saline (PBS) for $1 \mathrm{~h}$, the membranes were incubated with primary antibodies in PBS with $5 \%$ nonfat dry milk overnight at $4-8^{\circ} \mathrm{C}$, The following antibodies were used: anti-Keap1 mouse polyclonal antibody (1:2000, Santa Cruz, CA), anti-Nrf2 rabbit polyclonal antibody (1:3000, Santa Cruz, CA), anti-HO-1 mouse polyclonal antibody (1:1000, Santa Cruz, CA), and antibody against actin or lamin B1 (1:6000, Santa Cruz, CA). These antibodies were used to confirm equal loading for whole-cell extracts and nuclear extracts. After extensively washing with PBS, the membranes were incubated with horseradish peroxidase-conjugated secondary anti-mouse antibody or anti-rabbit antibody (1:2000, Santa Cruz, CA) for $1 \mathrm{~h}$ at room temperature. Antigen-antibody complexes were visualized with Chemiluminescent kit (Pierce). Protein levels were quantified using Quantity one software (Bio-Rad Life Science, Shanghai, China) to obtain the ratio of the optical density of the target protein to that of $\beta$-actin.

\section{Cell viability assay}

Drug sensitivity was calculated by the CCK-8 (Toyobo, Japan) assay. Cells were seeded at a density of $5 \times 10^{3}$ in 96 -well plates. After $24 \mathrm{~h}$, the medium was replaced with fresh medium with or without different concentration of 5-FU for $48 \mathrm{~h}$. Following this, an aliquot of $10 \mu \mathrm{L}$ of CCK-8 plus $100 \mu \mathrm{L}$ DMEM was added to each well and incubated for $2 \mathrm{~h}$. At last, the absorbance was measured using a microplate reader (reference wavelength $650 \mathrm{~nm}$ ) at $550 \mathrm{~nm}$. The IC $_{50}$ value of 5-FU was calculated using Statistical Package for the Social Sciences (SPSS) 16.0. Three independent experiments were performed.

\section{Measurement of Keap1 expression stability}

The cells were transfected with $100 \mathrm{nM}$ of miR-141 mimics and its negative control. After $48 \mathrm{~h}$, the cells were treated with actinomycin $(5 \mu \mathrm{g} / \mathrm{mL})$ or cycloheximide (CHX) $(10 \mu \mathrm{g} / \mathrm{mL})$. The cells were harvested at subsequent time intervals $(0 \mathrm{~h}$ and $10 \mathrm{~h}$ or $24 \mathrm{~h})$, and the mRNA and protein levels of Keap1 


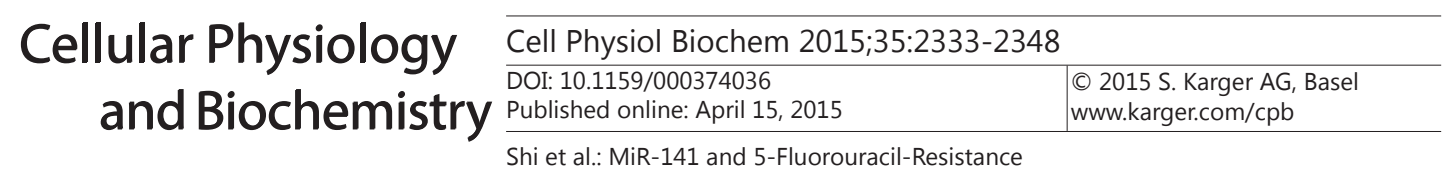

were determined by RT-PCR and western blot for indicated time. Housekeeping gene of glyceraldehyde 3-phosphate dehydrogenase (GADPH), which showed little decay over $6 \mathrm{~h}$, was used as an internal control. Results from the assays were processed using Prism 5.0 software (GraphPad; La Jolla, CA) to calculate the half-life of Keap1 in mRNA and protein levels

\section{Apoptosis assay}

The cells were transfected with $100 \mathrm{nM}$ miR-141 mimics, anti-miR-141, and miR-141 mimics in combination with anti-miR-141 (100 nM) and $100 \mathrm{nM}$ negative controls. After treatment with indicated doses of 5-FU for $48 \mathrm{~h}$, cell apoptosis was determined using Annexin-V-FITC apoptosis detection kit (BD, Franklin Lakes, New Jersey, USA). Briefly, $2.0 \times 10^{5}$ treated cells were re-suspended in $0.5 \mathrm{~mL}$ of binding buffer and were incubated with Annexin-V-FITC and propidium iodide (PI) for $15 \mathrm{~min}$ at room temperature in the dark. Two-color fluorescence-activated cell sorting (FACS) analysis (BD LSR II) was used to detect the cellular apoptosis by flow cytometry. The CellQuest Pro software was used for the acquisition and analysis of the data apoptosis assay.

\section{Statistical analysis}

The experiments were performed in triplicates and the data is expressed as mean $\pm \mathrm{SD}$. Comparisons made between treatments were determined using unpaired student's $t$-test. One-way analysis of variance (ANOVA) was used for comparing multiple groups with single controls. The GraphPad Prism 5.0 software was used for the data analysis

\section{Results}

Differential expression of miRNAs in HepG2 and HepG2/5-FU cells

To validate the correlation of miRNAs with 5 -FU resistance, the miRNA expression profiles were analyzed in HepG2 and HepG2/5-FU cells by miRNA microarrays. The differential expression of 15 miRNAs, including 6 up-regulated and 9 down-regulated miRNAs were found in HepG2/5-FU cells by $>2$-folds or $<0.5$-folds as compared to their parental counterparts (Table 1). To confirm the results of microarray analyses, the differentially expressed miRNAs were verified using qRT-PCR analysis, including miR-141, miR-21, miR27a, miR-155, miR-210, miR-134, miR-340, miR-145, miR-451, miR-19a, miR-148a, miR-565, miR-501, miR-29a, and miR-30a in HepG2 and HepG2/5-FU cells. Prospectively, the results were highly consistent with the differential expression profiles screened by the miRNA array (Fig. 1A). Furthermore, the expression of miR-141 in two 5-FU-resistant cancer cell variants, including SMMC-7721/5-FU and HuH7/5-FU derived from SMMC-7721 and HuH7 HCC cell-

Table 1. Differential expression of miRNA in 5-FU-resistant HepG2 cell-lines as compared to non-reistant cells

\begin{tabular}{llcc}
\hline miRNA & Chromosome & Overlapping transcripts & Fold change \\
\hline miR-141 & $12 \mathrm{p} 13$ & intergenic & 2.94 \\
miR-21 & $17 \mathrm{q} 23$ & intergenic & 2.76 \\
miR-27a & $19 \mathrm{p} 13$ & intergenic & 2.53 \\
miR-155 & $21 \mathrm{q} 21$ & intergenic & 2.34 \\
miR-210 & $11 \mathrm{p} 15$ & intergenic & 2.17 \\
miR-134 & $14 \mathrm{q} 32$ & intergenic & 2.02 \\
miR-340 & $5 \mathrm{q} 35$ & intergenic & 0.05 \\
miR-145 & $5 \mathrm{q} 33$ & intergenic & 0.12 \\
miR-451 & $17 \mathrm{p} 11$ & intergenic & 0.19 \\
miR-19a & $13 \mathrm{q} 31$ & Q75NE6-HUMAN & 0.27 \\
miR-148a & $7 \mathrm{p} 14$ & intergenic & 0.33 \\
miR-565 & $3 \mathrm{p} 21$ & intergenic & 0.37 \\
miR-501 & Xp11.2 & intergenic & 0.41 \\
miR-29a & $7 \mathrm{q} 32$ & intergenic & 0.47 \\
miR-30a & $6 \mathrm{q} 13$ & C6or155-003 & 0.49 \\
\hline
\end{tabular}


Fig. 1. (A) The level of differential expression of a panel of miRNAs were detected by qPCR in HepG2/5-FU as compared to HepG2 cell lines. The miR-141 is up-regulated in HepG2/5-FU as compared to HepG2 cells. The validated result of the 15 miRNAs suggests that the microarray data was consistent with the qPCR results. ${ }^{* *} p<0.01 v s$ parental cells. (B) qRT-PCR was performed to verify the levels of miR-141 in SMMC7721/5-FU and HuH7/5-FU cells as compared to the parental counterparts. U6 was used as an internal control and for normalization of the data. Columns: three independent experiments; data is expressed as mean $\pm \mathrm{SD}$, ${ }^{*} p<0.01$ vs parental cells.

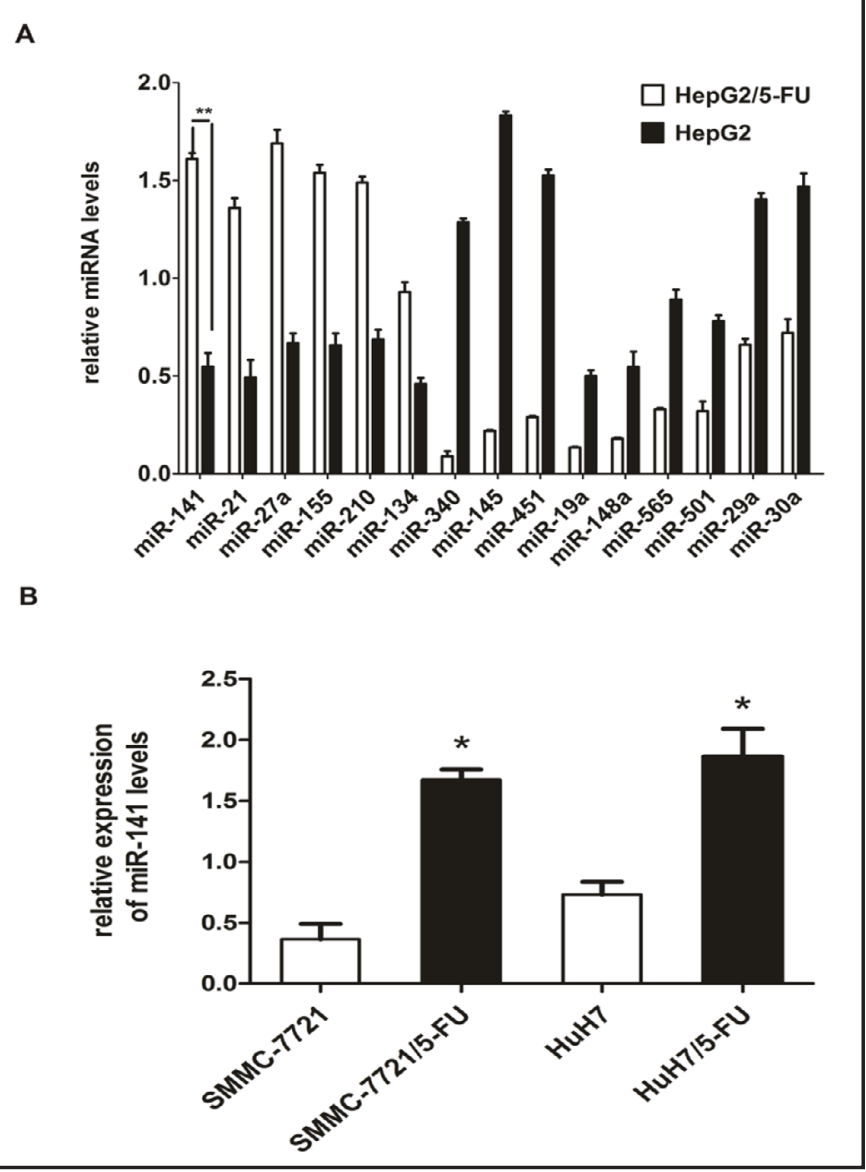

A

lines respectively, was confirmed using RT-PCR. The miR-141 was found to be significantly up-regulated by > 2-fold in SMMC-7721/5-FU and HuH7/5-FU cells as compared to their parental counterparts, which indicated that the association between miR-141 and 5-FU resistance is not a single cell-line-specific effect (Fig. 1B).

MiR-141 confers HCC cells resistance against 5-fluorouracil

The role of miR-141, miR-21, and miR-27a in 5-FU-induced resistance was investigated. The CCK-8 assay indicated that HepG2 cells transfected with mimics of miR-141, miR-21, and miR-27a exhibited markedly enhanced resistance to 5-FU as compared to the negative control groups (Fig. 2A). Since miR-141 exhibited the strongest chemoresistance to 5-FU, its role and mechanism in 5-FU resistance was further investigated.

To confirm and extend our findings, two additional HCC cell-lines, including SMMC7721 and HuH7, were used to confirm whether ectopic miR-141 expression also can induce 5-FU resistance. Since miR-141 exhibited the highest induction of 5-FU resistance around the $\mathrm{IC}_{50}$ dose of HepG2 cells (Fig. 2A), the HCC cell-lines were exposed to the IC $_{50}$ value of 5 -FU as determined for each of these cell lines (Table 2). Interestingly, overexpression of miR-141 significantly inhibited the 5-FU-induced cytotoxicity and enhanced 5-FU resistance in a dose-dependent manner in HepG2 cells (Fig. 2B). Similar results were obtained with the experiments performed in SMMC-7721 and HuH7 cells (Fig. 2B).

MiR-141 contributes to reduced susceptibility to 5-FU-induced apoptosis

The 5-FU is known to kill cancer cells by exhausting the antioxidant capacity of cancer cells and thus causing drug-induced apoptosis. The hypothesis is that the overexpression of miR-141 might play a role in the development of drug resistance by inhibiting 5-FU-induced apoptosis. To validate this hypothesis, the HepG2 and SMMC-7721 cells were transfected 
Fig. 2. (A) $100 \mathrm{nM}$ mimics of miR141, miR-21, and miR-27a were transferred to HepG2 cells. After $24 \mathrm{~h}$ of transfection, the cells were seeded in 96-well plates at a density of $5 \times 10^{3}$ per well for $12 \mathrm{~h}$ followed by treatment with $0,0.05$, 0.5 , and $5 \mu \mathrm{g} / \mathrm{mL} 5-\mathrm{FU}$ for $48 \mathrm{~h}$. The inhibition of cell viability was calculated using a CCK-8 reagent. ${ }^{*} p<0.05$ vs NC group, ${ }^{*} p<0.05$. (B) The cells were transfected with $0,25,50$, and $100 \mathrm{nM}$ mimics of miR-141 for $24 \mathrm{~h}$, and the cells were seeded in 96-well plates at a density of $5 \times 10^{3}$ cells/well. After $12 \mathrm{~h}$, the cells were treated with 5 -FU at their respective $\mathrm{IC}_{50}$ for $48 \mathrm{~h}$. The inhibition of cell viability was determined using a CCK-8 reagent. Columns: mean of three independent experiments; data is expressed as mean \pm SD. ${ }^{*} p<0.05$ vs 0 nM group; ${ }^{*} p<0.05$.

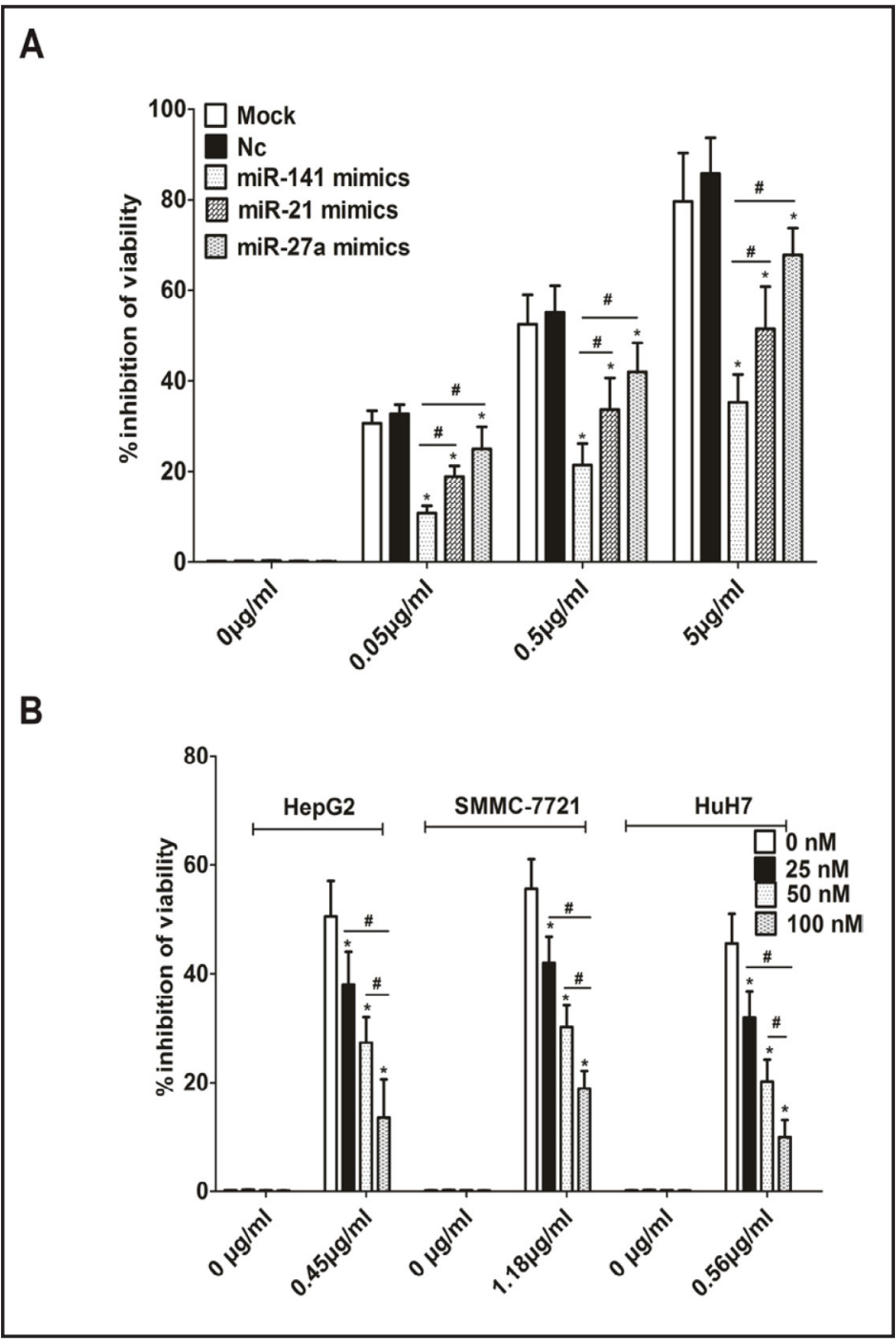

Table 2. Exposure of cells to different concentrations of 5-FU and calculation of IC50 value. Data is expressed as mean \pm SD of 3 independent experiments. ${ }^{* *} p<0.01$ vs Parental

\begin{tabular}{llc}
\hline Groups & IC50 value $(\mu \mathrm{g} / \mathrm{mL})$ & Resistant index/reversal index \\
\hline HepG2 & $0.45 \pm 0.03$ & - \\
HepG2/5-FU & $1.49 \pm 0.07^{* *}$ & 3.31 \\
SMMC-7721 & $1.18 \pm 0.24$ & - \\
SMMC-7721/5-FU & $3.59 \pm 0.44^{* *}$ & 3.04 \\
HuH7 & $0.56 \pm 0.07$ & - \\
HuH7/5-FU & $1.94 \pm 0.16^{* *}$ & 3.46 \\
\hline
\end{tabular}

with miR-141 mimics or negative control and were exposed to different concentrations of 5-FU. A marked decrease in apoptosic cells with annexin $\mathrm{V}$ staining was detected by flow cytometry in miR-141 mimics' transfected cells as compared to negative controls. Lower caspase 3 activity was also observed in miR-141 mimics' transfected cells as compared to control cells after indicated doses of 5-FU treatment for $24 \mathrm{~h}$. Conversely, the miR-141 inhibitors combined group recovered 5-FU-induced apoptosis in HepG2 and SMMC-7721 cells. In contrast, a significant increase in apoptosis and higher caspase 3 activity were 


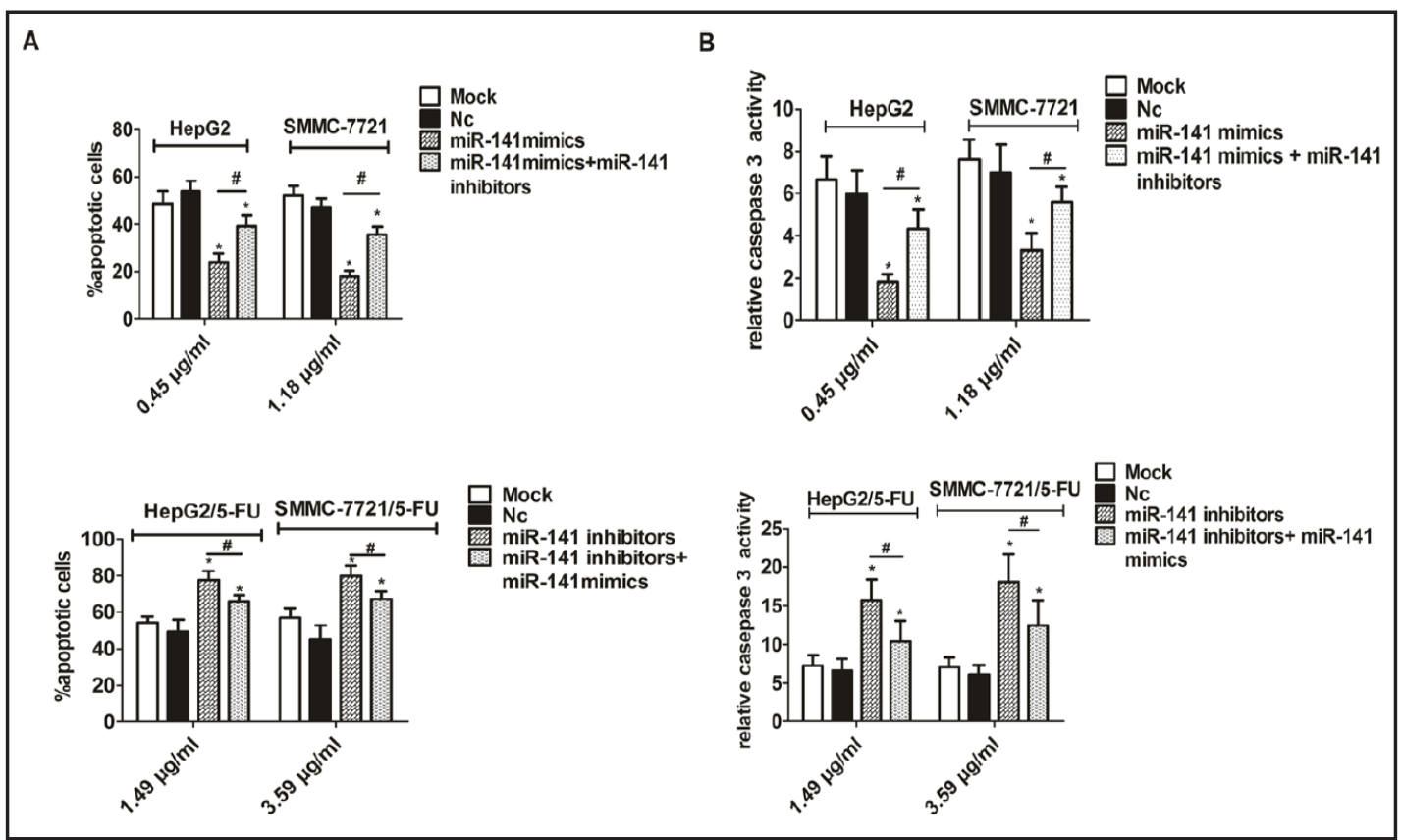

Fig. 3. HepG2 and SMMC-7721 cells were transfected with miR-141 mimics and its negative control, while HepG2/5-FU and SMMC-7721/5-FU cells were transfected with miR-141 inhibitor and its negative control. The miR-141 mimics combined anti-miR-141 group was used for rescue experiments in both parental and resistant cells. (A) Transfected cells were treated with indicated doses of 5-FU for $48 \mathrm{~h}$. The cells were subjected to apoptotic analysis by annexin-V/PI staining and flow cytometry. Bar graph indicates the relative percentages of apoptotic cells from three independent experiments. ${ }^{*} p<0.05$ vs NC group; \#p<0.05. (B) Transfected cells were seeded in 96 -well plates at $5 \times 10^{3}$ cells per well in triplicates. After $8 \mathrm{~h}$, the cells were treated with indicated doses of 5-FU for $24 \mathrm{~h}$. Caspase 3 activity was detected by Caspase-Glo L3/7 assay kit (Promega). Columns: mean of three independent experiments; data is expressed as mean \pm SD. ${ }^{*} p<0.05$ vs NC group; $\# p<0.05$.

observed in HepG2/5-FU and SMMC-7721/5-FU cells transfected with miR-141 inhibitors as compared to negative controls. Similarly, the miR-141 mimics combined group blocked 5-FU-induced apoptosis in 5-FU-resistant HepG2 and SMMC-7721 cells (Fig. 3A-B). These results indicated that miR-141 conferred 5-FU resistance in cancer cells by blocking 5-FUinduced apoptosis.

MiR-141 promotes Nrf2 nuclear translocation and activates Nrf2 pathway

Since miR-141 is capable of inhibiting the 5-FU-induced apoptosis and enhancing the resistance of cancer cells to 5-FU, the targets of miR-141 were investigated by three public miRNA databases (TargetScan, Pictar, and MicroRNA). A bioinformatics-based analysis identified PTEN, MSH2, MIBI, CUL3, and Keap1 as hypothetical target genes of miR-141. In addition, it was examined that whether overexpression of miR-141 could alter these predicted targets of proteins. The miR-141 mimic transfection did not alter the expression of PTEN, MSH2, MIBI, and CUL3; however, a clear and consistent reduction ( $>2$-fold) in Keap1 protein levels was observed in HepG2 cells (Fig. 4A). Therefore, Keap1 was chosen for further analysis because of the identification of one conserved targeting site matching the seed sequences for miR-141 within the Keap1 3'UTR by TargetScan5.1 miR target prediction algorithm (Fig. 4B).

A validated miR-141 targeting site was constituted in Keap1 mRNA 3'UTR

In order to confirm whether miR-141 could regulate its binding site within the Keap1 mRNA, 10 ng of pGL3-Keap1 3'UTR luciferase reporter plasmids were co-transfected with miR-141 mimics, anti-miR-141, or their negative controls (100 nM) in HepG2 and HepG2/5- 


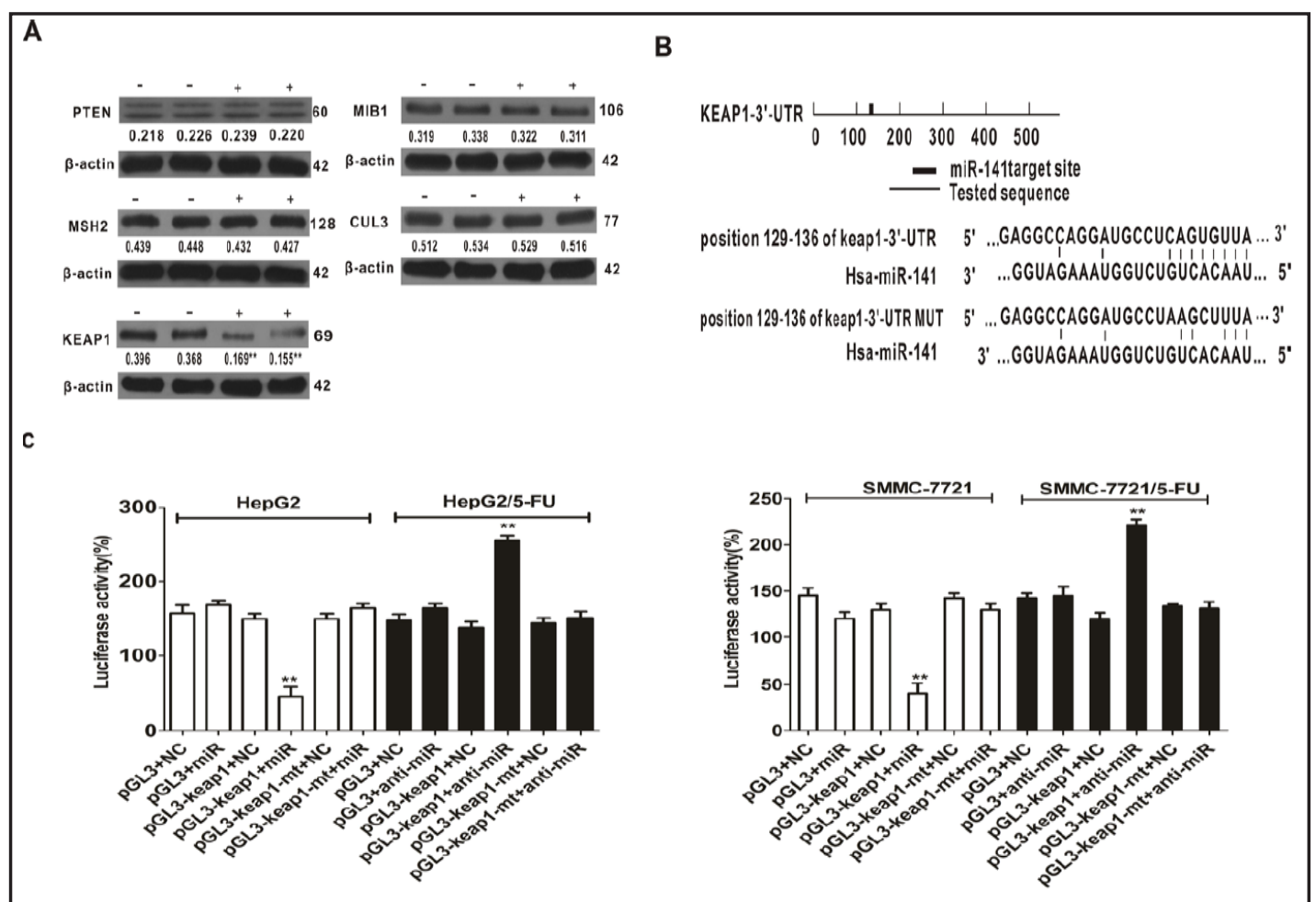

Fig. 4. (A) HepG2 cells were transfected with mimics of miR-141 or scrambled mimics and then subjected to western blotting using antibodies against PTEN, MIB1,MSH2, CUL3, Keap1, and $\beta$-actin. ${ }^{* *} p<0.01$ vs NC group. (B) One putative miR-141-binding site was identified in the region of the Keap1-3'UTR. The seed sequence of miR-141 (first 8 nucleotides) are complementary to the binding site in the UTR. Three nucleotides were mutated to generate mutant Keap1-3'UTR in the miR-141-binding site. (C-D) Luciferase assay in HepG2, SMMC-7721, HepG2/5-FU, and SMMC-7721/5-FU cell-lines. Wild-type (pGL3-Keap1-3'UTR) and mutagenized (Keap1-3'UTR -mut) reporter vectors were co-transfected with mimics or inhibitors of miR141 or negative controls. Columns: mean of three independent experiments; data is expressed as mean \pm SD. ${ }^{* *} p<0.01$ vs NC group or mut group.

FU cells. The cells were assayed by a luciferase reporter. The HepG2 cells transfected with pGL3-Keap1 3'UTR vector exhibited $>2.5$-fold reduction in the luciferase activity when cotransfected with miR-141 mimics ( $p<0.05)$. Conversely, the HepG2/5-FU cells transfected with pGL3-Keap1 3'UTR vector demonstrated $>1.5$-fold increase in the luciferase activity when co-transfected with miR-141 inhibitors $(p<0.05)$. The mutant pGL3-Keap1 3'UTR luciferase reporters were generated by mutating 3 bases of the predicted miR-141 target seeding sequence ( $C$ ( $C$ to $A$ ), AGU ( $U$ to $C$ ), G ( $G$ to $U$ ) UUA) in the cloned Keap1 3'UTR region (Fig. 4B). However, no significant change in the luciferase activity following the co-transfection of the mutagenized vector with miR-141 mimics or anti-miR-141 was observed. Similar results were also obtained in SMMC-7721 and SMMC-7721-5-FU cell-lines. Collectively, these results indicated a direct interaction between miR-141 and Keap1 mRNA in HCC-derived cell-lines (Fig. 4C-D).

\section{MiR-141 decreases Keap1 mRNA and protein stability}

The miRNAs can induce reduction of gene expression by miRNA degradation or blocking protein translation. In order to confirm the role of miR-141, the HepG2, SMMC-7721, and HuH7 cells, transfected with or without miR-141 mimics, were exposed to transcription or translation inhibitors, such as actinomycin D $(5 \mu \mathrm{g} / \mathrm{mL})$ or CHX $(10 \mu \mathrm{g} / \mathrm{mL})$ respectively. The endogenous levels of Keap1 mRNA or protein were determined by qRT-PCR or western blot analysis. It was found that both Keap1 mRNA and protein expression levels were decreased 
Fig. 5. (A-B). The cells were transfected with $100 \mathrm{nM}$ mimics of miR-141 or negative control. After $12 \mathrm{~h}$, the cells were treated with actinomycin D (5 $\mu \mathrm{g}$ / $\mathrm{mL})$ for $10 \mathrm{~h}$ or CHX $(10 \mu \mathrm{g} / \mathrm{mL})$ for 24 h. The stability of endogenous Keap1 mRNA and protein was detected by RTPCR or western blotting at the indicated times. Bar graph indicates the relative ratio of Keap1 expression to actin from three replicates. Data is expressed as mean \pm SD. ${ }^{*} p<0.05 ;{ }^{* *} p<0.01$ vs 0 h group.

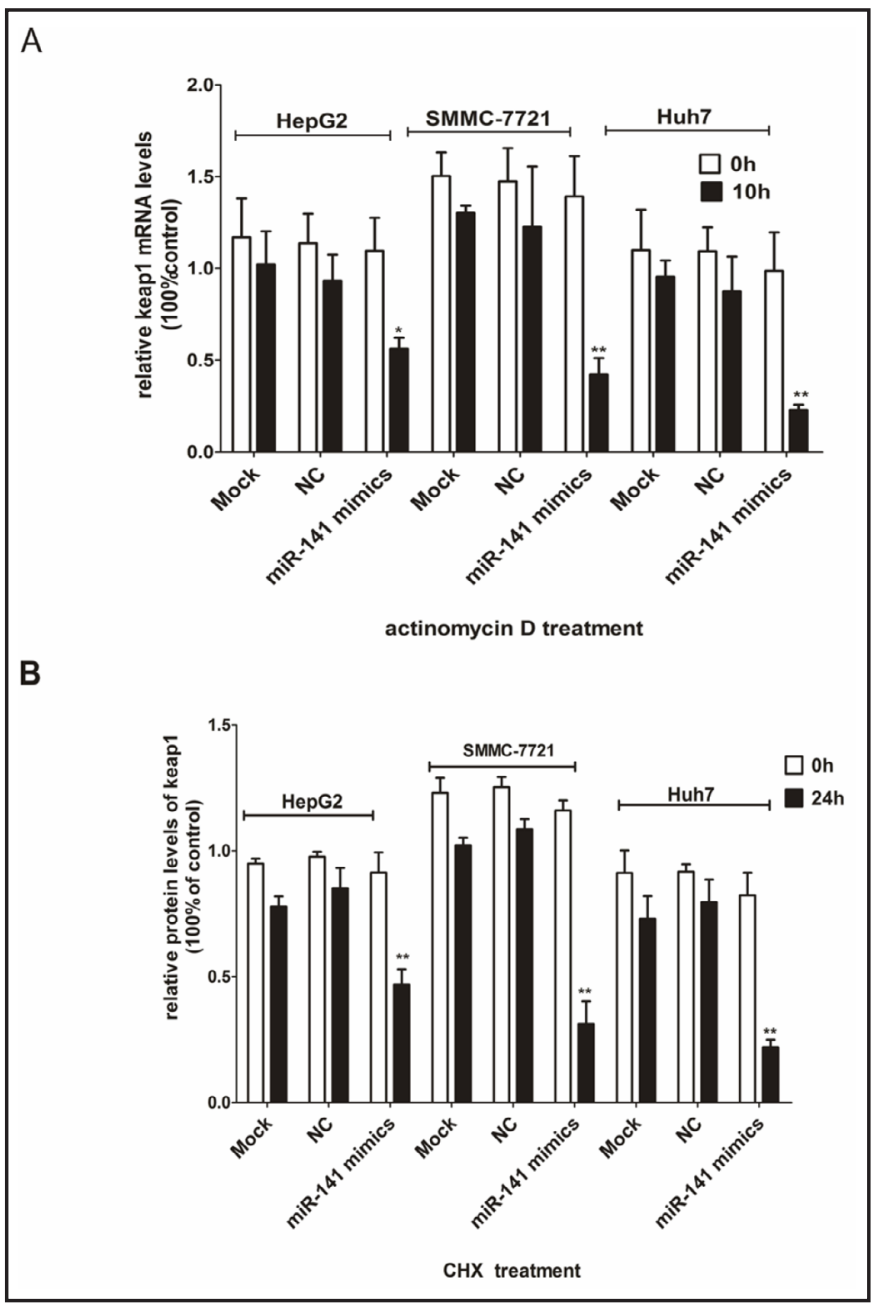

in miR-141 overexpressing cells as compared to control cells after actinomycin D or CHX treatment for indicated times respectively. These observations suggested that Keap1 is subject to modulation by miR-141 through alterations in mRNA and protein stability (Fig. $5 \mathrm{~A}-\mathrm{B})$.

MiR-141 targeting of Keap1 results in Nrf2 nuclear translocation and activation of Nrf2 pathway in a dose-dependent manner

The role of miR-141 in the regulation of Keap1 expression was confirmed by qRTPCR and western blot analysis. Briefly, the HepG2 and SMMC-7721 cells were transiently transfected with $100 \mathrm{nM}$ miR-141 mimics or miR-141 mimic in combination with miR-141 inhibitor $(100 \mathrm{nM})$ respectively. Transfection with the miR-141 alone reduced the expression of Keap1 (Fig. 6A) and enhanced the resistance (Fig. 6B) of these cells to 5-FUs in the celllines. Interestingly, the transfection with the miR-141 mimics combined with miR-141 antisense restored the expression of Keap1 and recovered 5-FU sensitivity (Fig. 6A-B).

Meanwhile, protein levels of nuclearNrf2 and total HO-1 were increased, whereas the level of caryoplasmic Nrf2 decreased in the miR-141 mimics transfected cells in a dose-dependent manner (Fig. 7A).It was also validated that whether the up-regulation of miR-141 promoted the activation of Nrf2 pathway: The HO-1-ARE luciferase plasmid and control vector (10 ng) were transiently transferred in the HepG2 and SMMC-7721 cells, and transfected with different concentrations of miR-141 mimics or miR-141 mimic combined with anti-miR-141 (100 nM). The results have demonstrated that ARE-driven luciferase activity was enhanced in a dose-dependent manner and the inducing effect was partly 
A

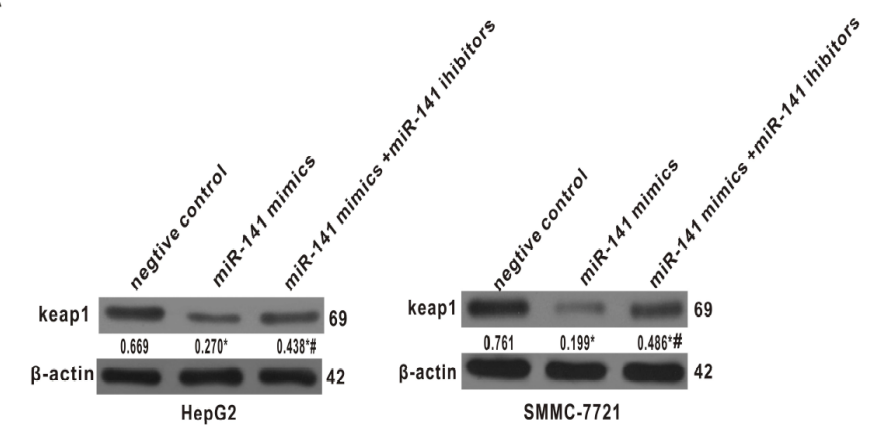

B

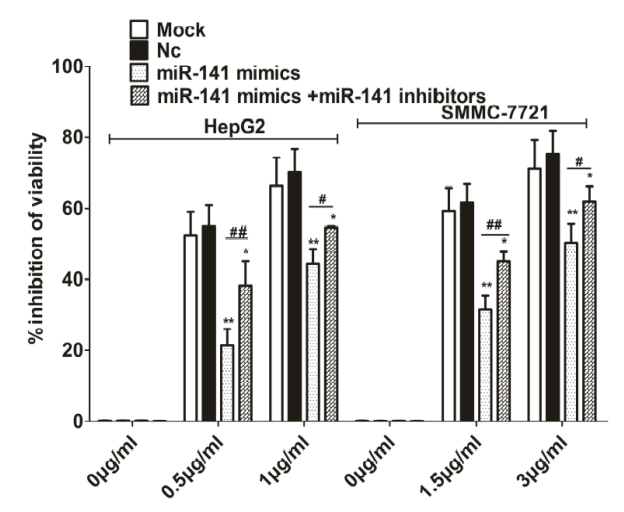

Fig. 6. (A) The cells were co-transfected with $100 \mathrm{nM}$ miR-141 mimics or in combination with anti-miR-141. Expression of Keap1 was detected by western blotting. $\beta$-actin was used as a loading control (Ctr). ${ }^{*} p<0.05$ vs NC group; ${ }^{~} p<0.05$ vs miR-141 mimics group. (B) The cells were seeded in 96 -well plates at $5 \times 10^{3}$ cells per well in triplicates followed by treatment with the indicated concentrations of 5-FU for $48 \mathrm{~h}$. The inhibition of cell viability was detected. Columns: mean of three independent experiments; data is expressed as mean \pm SD. ${ }^{*} p<0.05 ;{ }^{* *} p<0.01$ vs NC group; ${ }^{\#} p<0.05 ;{ }^{\# \#} p<0.01$.

blocked by miR-141 inhibitor in the combined group (Fig. 7B). The enhanced expression of Nrf2 and HO-1 was also observed in the miR-141 mimics plus anti-miR-141 NC group (100 $\mathrm{nM}$ ) as compared to miR-141 mimics NC plus anti- miR-141 NC group (100 nM; Fig. 7C). Similarly, the up-regulation of Nrf2 and HO-1 by miR-141 mimics was partly blocked by the miR-141inhibitor in the combined group (Fig. 7C).

To further validate these results, the HepG2 cells were transfected with miR-141 mimics alone or miR-141 mimics NC (100 nM) or $100 \mathrm{nM}$ miR-141 mimics plus 50 ng Keap1-FLAG plasmids. Results from western blotting have shown that transfection with miR-141 mimics reduced the expression of Keap1, whereas enhanced the expression of Nrf2 and HO-1 (Fig. 8A), thereby, resulting in the resistance of the cells to 5-FU (Fig. 8B). However, restoring the expression of Keap1 by co-transfecting miR-141 mimics and Keap1-FLAG plasmid decreased the expression of Nrf2 and HO-1 (Fig. 8A), thereby recovering the 5-FU sensitivity (Fig. 8B). However, the miR-141 mimics do not alter the levels of Keap1 protein expressed by exogenous Keap1-FLAG (Fig. 8A). This can be explained by the absence of 3'UTR in the exogenously expressed Keap1 mRNA.

These findings demonstrated that miR-141 targeting Keap1 resulted in the translocation of Nrf2 into the nucleus and activation of Nrf2 pathway, thereby conferring the 5-FU resistance to HCC-derived cell lines. 
Fig. 7. (A) HepG2 and SMMC-7721 cells were treated with $0,25,50$, and $100 \mathrm{nM}$ mimics of miR-141 for 24 h. Cell lysates were analyzed by immunoblotting using anti Nrf2 (nucleus and caryoplasm), HO1 , and $\beta$-actin antibodies. ${ }^{*} p<0.05$ vs $0 \mathrm{nM}$ group. (B) HO-1-ARE-luciferase plasmid or control vector was transiently transferred into HepG2 or SMMC-7721 cells and transfected with different concentration of miR-141 mimics or miR-141 mimic in combination with anti-miR-141 (100 nM), and tBHQ was used as a positive control. The induced fold of luciferase activity for cell lysates was analyzed by normalizing the transfection efficiency and dividing the values of each experiment relative to the control. Columns: mean of three in-
A

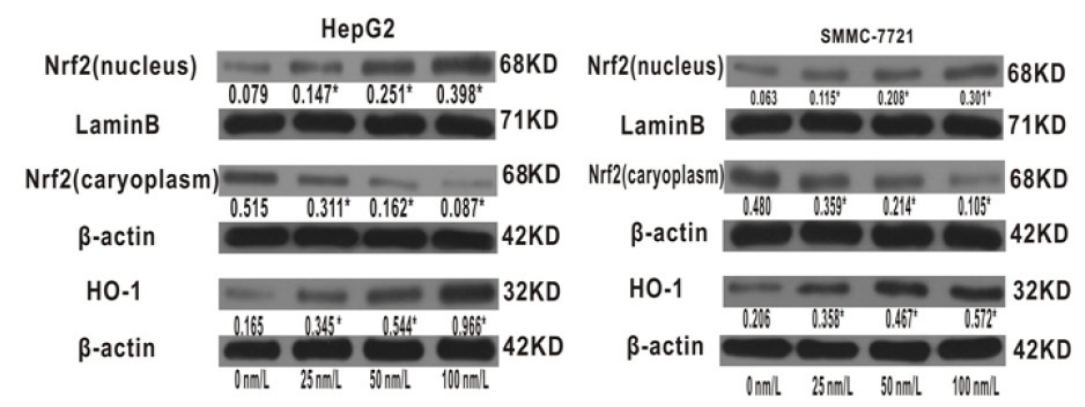

B
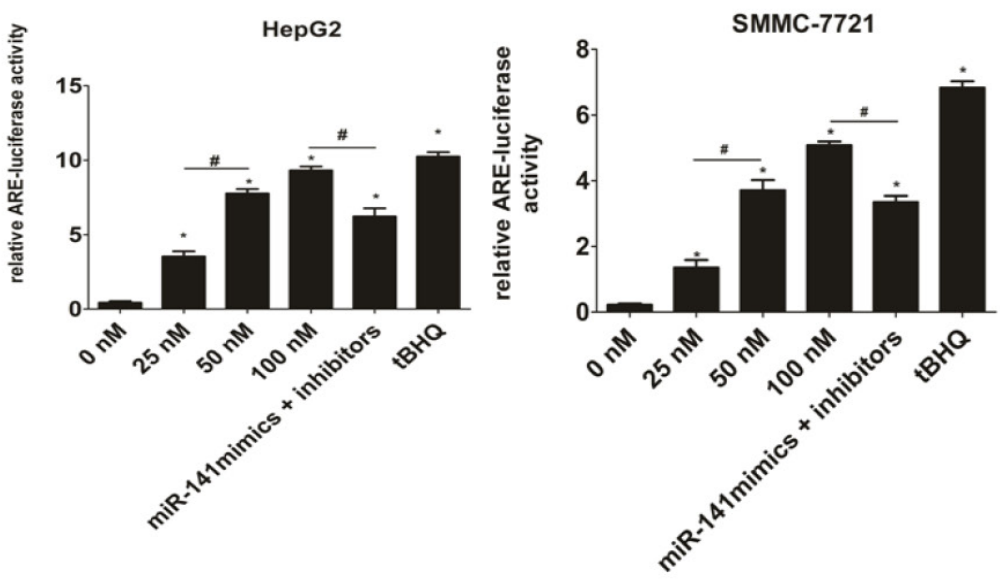

C

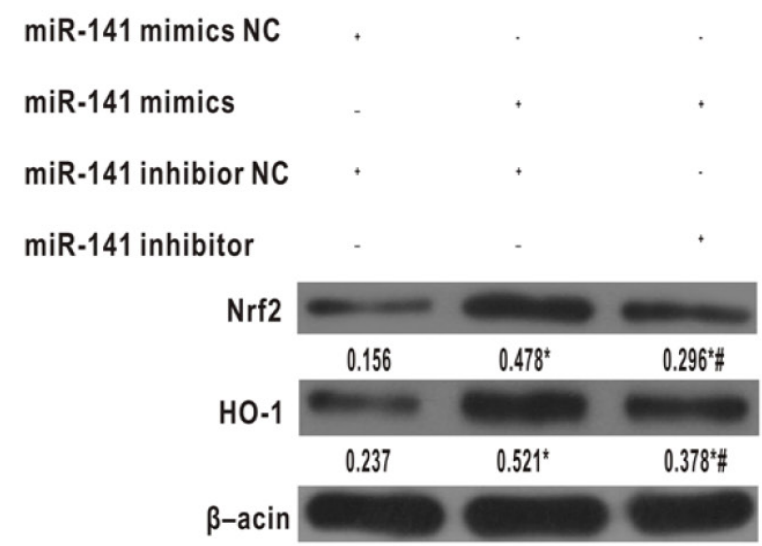

dependent experiments. $p<0.05$ vs 0 nM group; ${ }^{\#} p<0.05$. (C) HepG2 cells were transfected with miR-141 mimics NC plus anti- miR-141 NC (100 nM), miR-141 mimics plus anti-miR-141 NC (100 nM), or miR-141 mimics plus anti- miR-141 (100 nM) for $48 \mathrm{~h}$. Cell lysates were prepared for western blotting using antibodies against Nrf2 or HO-1. " $p<0.05$ vs NC group; ${ }^{\#} p<0.05$ vs miR-141 mimics plus anti-miR-141 NC group.

\section{Discussion}

Recent research findings have confirmed the well-established role of miRNA on an oncogenic or tumor suppressor-like function mediated cell proliferation, differentiation, and apoptosis [13]. However, the elucidation of the molecular mechanisms involving in the development of chemoresistance, such as to 5-FU remains largely unexplored. In this report, KARGER 
Fig. 8. (A) HepG2 cells were transfected with miR-141 mimics NC, or miR-141 mimics alone (100 nM) or in combination with 50 ng Keap1-FLAG plasmids. The levels of Keap1, Nrf2, and HO-1 were detected by western blotting. $\beta$-actin was used as a loading control. (B) The transfected HepG2 were seeded in 96well plate at a density of $5 \times 10^{3}$ cells per well and were treated with $0,0.5$, and $1 \mu \mathrm{g} / \mathrm{mL} 5$-FU for $48 \mathrm{~h}$. The inhibition of cell viability was detected by CCK-8. Bar graph indicates the percentage of viability inhibition from three replicates. Data is expressed as mean \pm SD. ${ }^{*} p<0.05$ vs NC group; ${ }^{\#} p<0.05$ vs miR-141 mimics group.

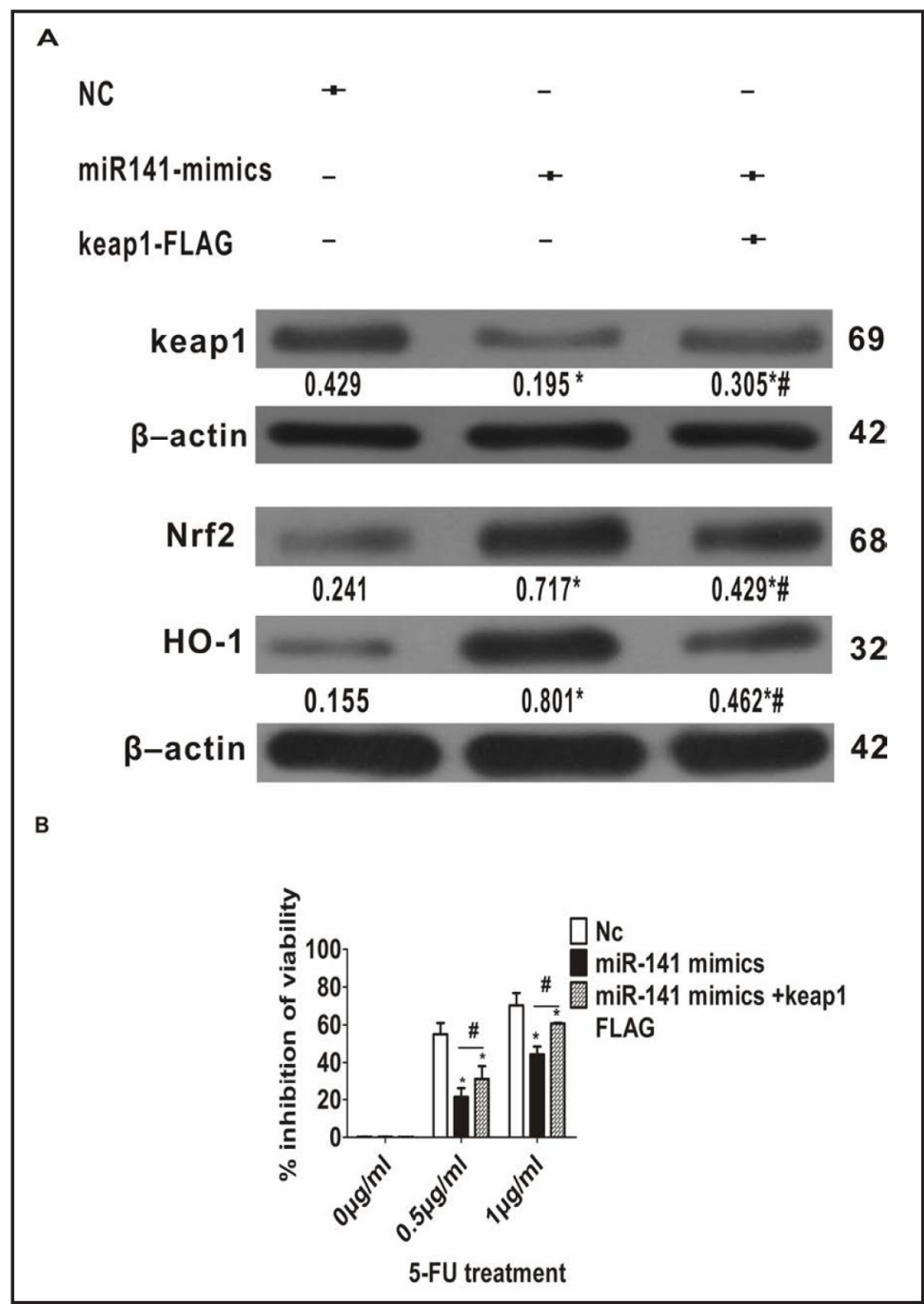

by comparing alteration in the expression of miRNA profiles between HepG2 and HepG2/5FU cells (Table 1), it was observed that the majority of the highly expressed miRNAs in 5-FU-resistant cells exhibited the properties of oncogenes, such as miR-21, miR-27a, and miR-155 [14-16]. Reduced expression of miRNAs, such as miR-340, miR-145, and miR451 was previously described as tumor suppression [17]. 5-FU resistance is a malignant phenotype; therefore, the results of our microRNA assay are in agreement with previous studies validating the profiling findings.

By validating the most abundantly expressed levels of miR-141, miR-21, and miR-27a, and investigating their effects on 5-FU induced resistance (Fig. 1A and 2A), it was observed that miR-141 strongly induced 5-FU resistance in HepG2 cell-lines in a dose-dependent manner in different concentrations of 5-FU (Fig. 2). A lower percentage of apoptotic cells were also identified in miR-141 transfected cells by annexin $\mathrm{V}$ staining after 5-FU exposure (Fig. 3A), which was further verified by the detection of caspase 3 activity (Fig. 3B). These findings suggested that the anti-apoptotic effect is a crucial mechanism for miR-141mediated 5-FU resistance in HCC cell-lines. Additionally, the miR-141 inhibitors promotes apoptosis in 5-FU-resistant cells (Fig. 3) suggesting that miR-141 plays a critical role in the development of 5-FU resistance.

The miR-141 is one of the members of the miR-200 family, which plays a pivotal role in the maintenance of cancer stem cells and regulation of the epithelial-to-mesenchymal transition $[18,19]$. However, the potential role of the miR-200 family, especially the role of miR-141 in chemotherapy of HCC is limited. In the present study, it has been demonstrated 
that miR-141 mimic transfection did not result in decreased expression of PTEN, MSH2, MIBI, and CUL3. However, the altered expression in of Keap1 in HepG2 cells showed that there might be an underlying mechanism, which requires validation for 5 -FU-mediated phenotype of miR-141 overexpression by continuous 5-FU exposure to HCC cell-lines (Fig. 4A).

Erythroid transcription factor NFE2-L2 plays a critical role in activating the expression of cellular detoxifying enzymes. Under normal conditions, the expression of Nrf2 is mainly modulated by the interaction of Nrf2 with (Keap1), which leads to the degradation of Nrf2 by the ubiquitin-proteasome pathway. Upon exposure to electrophiles and oxidative stress, Nrf2 dissociates from Keap1 and translocate into the nucleus to activate the constitutive expression of downstream phase II detoxifying enzymes and antioxidant proteins especially for $\mathrm{NAD}(\mathrm{P}) \mathrm{H}$ : quinone oxidoreductase1 (NQO1) and HO-1, which detoxifies cancer drugs by attenuating drug-induced oxidative stress and apoptosis [20]. Recent studies have demonstrated that chemoresistance in cancer therapy is associated with the constitutive activation of the Nrf2-mediated antioxidant and detoxification processes [21]. In order to validate the molecular mechanism of miR-141 overexpression in 5-FU resistance, Keap1 was identified as a direct target of miR-141 containing a conserved complementary site within the Keap1 mRNA 3'UTR using TargetScan5.1 prediction algorithm (Fig. 4B). The results have further highlighted the molecular mechanisms by which miR-141 reduces Keap1 mRNA expression. Initially, the ability of miR-141 to modulate posttranscriptional level of Keap1 expression was evaluated by luciferase reporter assay. In this study, we have demonstrated that miR-141 reduces wild-type Keap1-3'UTR luciferase reporter activity, which is eliminated due to the mutation of the miR-141 targeting seed sequence within the Keap1-3'UTR (Fig. 4C-D).

In addition, by using the HCC parent and resistant cell-lines to explore the impact of miR141 on Keap1 expression, it was observed that the levels of Keap1 mRNA were reversibly related with the miR-141 expression, and the ectopic expression of miR-141 alone downregulated the levels of Keap1mRNA and protein in HCC cell-lines (Fig. 5 and 6). Mechanically, this reduction in Keap1 levels promoted Nrf2 nuclear translocation and activated Nrf2dependent HO-1 expression, thereby resulting in the enhanced resistance of these cells to 5-FU. Conversely, these effects were partly eliminated in the miR-141 mimics combined with miR-141 antisense group (Fig. 6-8). Based on the above discussion, we opined that miRNAs can suppress the target gene expression by mRNA cleavage or inhibition of translation. Concerning the latter mechanism of action, the inhibition of miRNA-dependent translational of target gene may include multiple steps of protein translation [22]. Moreover, the specific proteases, although unknown, might be involved in the nascent polypeptides degradation through 3'UTR-tethered miRNA-RISC complex. This speculated mechanism may explain the current observation that miR-141 interferes with the Keap1 protein stability, thereby leading to the reduced protein production (Fig. 5A-B). Further research, however, should focus on the exact mechanism by which the miR-141 mediates Keap1 protein degradation.

The miR-200 family, including 2 clusters: miR-200b/200a/429 located on chromosome $1 \mathrm{p} 36$ and miR-200c/141 located on chromosome 12p13, has been reported to play a critical role in the susceptibility to cancer chemotherapy [23]. It has been reported that overexpression of miR-429, miR-200a, and miR-141 in ovarian cancer cell-lines enhances the sensitivity to paclitaxel [24]. Conversely, another observation suggested that the overexpression of miR-141 in ovarian cancer cell-lines increases cisplatin resistance [25]. These findings indicated the complex relationship between the treatment response and the miR-200 family. In this study, we have demonstrated that miR-141 plays a key role in 5-FU resistance by down-regulating Keap1 expression, thereby reactivating the Nrf2-dependent antioxidant pathway. Collectively, the impact on the expression of miRNA influences the targets in cell type-specific and phenotype-specific manner [26]. Thus, diverse effects might emerge upon overexpression or knockdown of miRNA may occur depending on the types of cancer cells.

Taken together, the present study demonstrated, for the first time, that miR-141 confers 5-FU resistance by suppressing Keap1 expression, thereby activating the Nrf2-

\section{KARGER}


Shi et al.: MiR-141 and 5-Fluorouracil-Resistance

dependent antioxidant pathway. This suppression may potentially serve as a therapeutic target for overcoming 5-FU resistance in HCC cells. These novel findings have a lot of crucial implications in the development of targeted therapeutics for overcoming 5-FU resistance.

\begin{abstract}
Abbreviations
HCC (Hepatocellular Carcinoma); 3'UTR (Untranslated Regions); qRT-PCR (Quantitative Real Time- Polymerase Chain Reaction); FBS (Fetal Calf Serum).

\section{Acknowledgments}

This project was supported by the Zhejiang Provincial Natural Science Foundation of China (LQ13H160021,LY12H20001)) and the Wenzhou Municipal Science and Technology Bureau (Y20120125) and the National Basic Research Program of China (973 Program, 2012CB720605)
\end{abstract}

\title{
Disclosure Statement
}

The authors declare no conflict of interest.

\section{Reference}

1 Bertino G, Demma S, Ardiri A, Proiti M, Gruttadauria S, Toro A, Malaguarnera G, Bertino N, Malaguarnera M, Di Carlo I: Hepatocellular carcinoma: novel molecular targets in carcinogenesis for future therapies. Biomed Res Int 2014;2014:203693.

2 Meng L, Yang L, Zhao X, Zhang L, Zhu H, Liu C, Tan W: Targeted delivery of chemotherapy agents using a liver cancer-specific aptamer. PLoS One 2012;7:e33434.

3 Liu M, Jiang L, Guan XY: The genetic and epigenetic alterations in human hepatocellular carcinoma: a recent update. Protein Cell 2014;10.1007/s13238-014-0065-9.

4 Greene CM, Varley RB, Lawless MW: MicroRNAs and liver cancer associated with iron overload: therapeutic targets unravelled. World J Gastroenterol 2013;19:5212-5226.

5 Perell K, Vincent M, Vainer B, Petersen BL, Federspiel B, Moller AK, Madsen M, Hansen NR, Friis-Hansen L, Nielsen FC, Daugaard G: Development and validation of a microRNA based diagnostic assay for primary tumor site classification of liver core biopsies. Mol Oncol 2014;10.1016/j.molonc.2014.07.015.

6 Fazi F, Blandino G: MicroRNAs: Non Coding Pleiotropic Factors in Development, Cancer Prevention and Treatment. Microrna 2013;2:81.

7 Yang H, Kong W, He L, Zhao JJ, O'Donnell JD, Wang J, Wenham RM, Coppola D, Kruk PA, Nicosia SV, Cheng JQ: MicroRNA expression profiling in human ovarian cancer: miR-214 induces cell survival and cisplatin resistance by targeting PTEN. Cancer Res 2008;68:425-433.

8 Ye G, Fu G, Cui S, Zhao S, Bernaudo S, Bai Y, Ding Y, Zhang Y, Yang BB, Peng C: MicroRNA 376c enhances ovarian cancer cell survival by targeting activin receptor-like kinase 7 : implications for chemoresistance. J Cell Sci 2011;124:359-368.

9 Zhang H, Luo XQ, Feng DD, Zhang XJ, Wu J, Zheng YS, Chen X, Xu L, Chen YQ: Upregulation of microRNA$125 \mathrm{~b}$ contributes to leukemogenesis and increases drug resistance in pediatric acute promyelocytic leukemia. Mol Cancer 2011;10:108.

10 Fujita Y, Kojima K, Hamada N, Ohhashi R, Akao Y, Nozawa Y, Deguchi T, Ito M: Effects of miR-34a on cell growth and chemoresistance in prostate cancer PC3 cells. Biochem Biophys Res Commun 2008;377:114119. 
11 Bai S, Nasser MW, Wang B, Hsu SH, Datta J, Kutay H, Yadav A, Nuovo G, Kumar P, Ghoshal K: MicroRNA-122 inhibits tumorigenic properties of hepatocellular carcinoma cells and sensitizes these cells to sorafenib. J Biol Chem 2009;284:32015-32027.

12 Do MT, Kim HG, Khanal T, Choi JH, Kim DH, Jeong TC, Jeong HG: Metformin inhibits heme oxygenase-1 expression in cancer cells through inactivation of Raf-ERK-Nrf2 signaling and AMPK-independent pathways. Toxicol Appl Pharmacol 2013;271:229-238.

13 Li Y, Ahmad A, Kong D, Bao B, Sarkar FH: Targeting MicroRNAs for personalized cancer therapy. Med Princ Pract 2013;22:415-417.

14 Ma X, Choudhury SN, Hua X, Dai Z, Li Y: Interaction of the oncogenic miR-21 microRNA and the p53 tumor suppressor pathway. Carcinogenesis 2013;34:1216-1223.

15 Wu XJ, Li Y, Liu D, Zhao LD, Bai B, Xue MH: miR-27a as an oncogenic microRNA of hepatitis B virus-related hepatocellular carcinoma. Asian Pac J Cancer Prev 2013;14:885-889.

16 Rather MI, Nagashri MN, Swamy SS, Gopinath KS, Kumar A: Oncogenic microRNA-155 down-regulates tumor suppressor CDC73 and promotes oral squamous cell carcinoma cell proliferation: implications for cancer therapeutics. J Biol Chem 2013;288:608-618.

17 Gits CM, van Kuijk PF, Jonkers MB, Boersma AW, Smid M, van Ijcken WF, Coindre JM, Chibon F, Verhoef C, Mathijssen RH, den Bakker MA, Verweij J, Sleijfer S, Wiemer EA: MicroRNA expression profiles distinguish liposarcoma subtypes and implicate miR-145 and miR-451 as tumor suppressors. Int J Cancer 2014;135:348-361.

18 Burk U, Schubert J, Wellner U, Schmalhofer O, Vincan E, Spaderna S, Brabletz T: A reciprocal repression between ZEB1 and members of the miR-200 family promotes EMT and invasion in cancer cells. EMBO Rep 2008;9:582-589.

19 Gregory PA, Bert AG, Paterson EL, Barry SC, Tsykin A, Farshid G, Vadas MA, Khew-Goodall Y, Goodall GJ: The miR-200 family and miR-205 regulate epithelial to mesenchymal transition by targeting ZEB1 and SIP1.

Nat Cell Biol 2008;10:593-601.

20 Chen X, Liu J, Chen SY: Over-expression of Nrf2 diminishes ethanol-induced oxidative stress and apoptosis in neural crest cells by inducing an antioxidant response. Reprod Toxicol 2013;42:102-109.

21 Jiang T, Chen N, Zhao F, Wang XJ, Kong B, Zheng W, Zhang DD: High levels of Nrf2 determine chemoresistance in type II endometrial cancer. Cancer Res 2010;70:5486-5496.

22 Reich J, Snee MJ, Macdonald PM: miRNA-dependent translational repression in the Drosophila ovary. PLoS One 2009;4:e4669.

23 Diaz T, Tejero R, Moreno I, Ferrer G, Cordeiro A, Artells R, Navarro A, Hernandez R, Tapia G, Monzo M: Role of miR-200 family members in survival of colorectal cancer patients treated with fluoropyrimidines. J Surg Oncol 2014;109:676-683.

24 Leskela S, Leandro-Garcia LJ, Mendiola M, Barriuso J, Inglada-Perez L, Munoz I, Martinez-Delgado B, Redondo A, de Santiago J, Robledo M, Hardisson D, Rodriguez-Antona C: The miR-200 family controls betatubulin III expression and is associated with paclitaxel-based treatment response and progression-free survival in ovarian cancer patients. Endocr Relat Cancer 2011;18:85-95.

25 van Jaarsveld MT, Helleman J, Boersma AW, van Kuijk PF, van Ijcken WF, Despierre E, Vergote I, Mathijssen RH, Berns EM, Verweij J, Pothof J, Wiemer EA: miR-141 regulates KEAP1 and modulates cisplatin sensitivity in ovarian cancer cells. Oncogene 2013;32:4284-4293.

26 Gebeshuber CA, Zatloukal K, Martinez J: miR-29a suppresses tristetraprolin, which is a regulator of epithelial polarity and metastasis. EMBO Rep 2009;10:400-405. 